FRANK JACKSON

\title{
COLOUR FOR REPRESENTATIONALISTS
}

\begin{abstract}
Redness is the property that makes things look red in normal circumstances. That seems obvious enough. But then colour is whatever property does that job: a certain reflectance profile as it might be. Redness is the property something is represented to have when it looks red. That seems obvious enough. But looking red does not represent that which looks red as having a certain reflectance profile. What should we say about this antinomy and how does our answer impact on the contest between realism and subjectivism about colour? I address the issues through the lens of a representationalist position on colour experience.
\end{abstract}

\section{THE VIA MEDIA}

There have always been two pressures operating on us when we think about colour. One pushes us towards some kind of realism, the other towards some kind of subjectivism.

Here is the line of thought that favours realism. We see colours as properties of the world around us. Our judgements about colours are the product of looking out, not in. We acknowledge that some conditions are better than others for making correct judgements about colour, that it is better to have a careful look rather than a cursory one, and that sometimes, after taking a careful look, it is right to change our minds about something's colour. Above all, we think of colour as a property of things in the world to which we are responding. When $\mathrm{X}$ looks red to us, we are in a state that is putatively a causal response to X's redness and, moreover, a state that represents that $\mathrm{X}$ is a certain way. Something's looking red to me does not represent how I am, or how my fellow humans are; it represents that what I am looking at is thus and so.

These remarks can be thought of as a kind of job description. Colour is a feature of the world around us, is a property we make judgements about when we look at objects, is the typical cause of 
something's looking coloured, is better assessed in some conditions than others, is the feature that X's looking red represents X as having, and so on. If nothing satisfies this job description, we should go eliminativist about colour. We should not embrace subjectivism. We might make a nod in the direction of subjectivism as a way of explaining why the world seems coloured. Colour experiences and dispositions to look coloured would, in this case, be part of an account of why colour seems to be a feature of our world although in reality it isn't: ripe tomatoes are no more red than are red afterimages, but in both cases there is an illusion of colour. If, on the other hand, some property does satisfy the job description, we should identify colour with that property. Some hold that a suitable refinement and extension of reflectances satisfies the job description. If reflectance profile RRP satisfies the job description for red, then red $=\mathrm{RRP}$, and we get a version of physical realism about colour.

The line of thought that pushes us towards subjectivism points out that our access to colour is via our experience of colour, and that this is a highly non-accidental fact. The fundamental reason we have for thinking that ripe tomatoes are red is that they look red. By way of contrast, we have many ways of arriving at justified opinions about something's shape that are independent of the shape it looks to havethrough the distinctive interaction patterns of shaped objects, through how the object in question feels, by measuring sides and angles and putting the information together in the right way, and so on. Moreover, colour seems to be a property our senses bring to the world. The physical sciences have no fundamental need for colour in their explanations. Colour enters the picture in virtue of certain highly distinctive effects of the physical world on creatures with certain kinds of structures in their eyes and brains.

It is considerations like these that lead many to hold that a biconditional like ' $\mathrm{X}$ is red iff $\mathrm{X}$ looks red to normal subjects in normal circumstances' is, when suitably belled and whistled, a priori. Indeed, some of the many say that this puts matters the wrong way around: the a priori status of the biconditional is independently plausible, and this in itself gives us strong reason to hold some kind of subjectivist or dispositionalist account of colour. ${ }^{1}$

Once upon a time I thought that there was a simple way to reconcile these two independently plausible lines of thought. ${ }^{2}$ It was to hold, first, that colour is a perfectly objective property of the world around us. Colour is the property that is the typical cause of things looking coloured and is the property our sense of sight is getting putative information about when things look coloured. This property 
is an objective property of our world, and may well be some kind of reflectance property if what others tell me is right. And, second, we should hold that what makes that property colour is, in large part, what it does to us, especially by way of making things look coloured in the right circumstances. The same goes for the various colours. Redness is a perfectly objective feature of the world, being say a reflectance profile we might label RRP. But what makes RRP redness is in large part what it does to us, especially by way of making things look red to us in certain circumstances. In consequence, being red can and should be unpacked in terms of being red for such and such creatures in so and so circumstances (with 'real' colour being analysed in terms of apparent colour in one way or another). But this is consistent with redness itself - redness for such and such a creature in so and so circumstances - being whatever property causes in the right way things to look red to those creatures in those circumstances.

The illustrative analogy is with poisons. Arsenic is a poison. It is a perfectly objective feature of our world. No-one is a subjectivist about arsenic, Berkley aside. However, what makes arsenic a poison is something about its relation to the creatures it poisons. In consequence, being a poison can and should be unpacked in terms of being a poison for such and such creatures in so and so circumstances, and being 'really' poisonous makes no sense except inasmuch as it is understood, in one way or another, in terms of being poisonous for... in ....

We seemed to have an attractive via media. We might debate many a detail but there appears to be a way of looking at the problem of colour that makes sense of the two separately compelling lines of thought.

I now think this is a mistake. This is because I now think, in the company of many, that we should be intensionalists or representationalists about perceptual experience, and if representationalism about colour experience is right - if what a colour experience is like is exhausted by how it represents things to be - then the via media is undermined in a fairly radical way. We must move to a more objectivist position on colour.

I will make some brief remarks in support of representationalism but it is a big topic in its own right. ${ }^{3}$ My main concern is to explain how representationalism undermines the simple via media I once found so attractive.

The paper proceeds as follows. I start with what I call the opacity puzzle. It suggests that we must think of the representational content of colour experience in a certain way. I then say a little about representationalism. This puts us in a position to spell out its impact on the via media. I conclude by explaining the famous biconditional's 
appeal without resorting to any kind of subjectivism or dispositionalism about colour; in addition, I respond briefly to a possible rearguard action by subjectivists-cum-dispositionalists.

\section{THE OPACITY PUZZLE}

Although I now think the via media needs to be rethought, one part of it remains, in my view, all but axiomatic. This is the part about colour being a putative feature of our world to which we are responding when something looks a certain colour, red, say. Colours are the putative causes of certain distinctive perceptual experiences, and that is a key part of what's involved in seeing colour and of our concept of colour.

Equally, it is all but axiomatic that colour experience is representational. When $\mathrm{X}$ looks red to you, you are in a state that represents that $\mathrm{X}$ is a certain way. Typically, you will also be in a state that represents that $\mathrm{X}$ is in a certain location relative to oneself, a certain shape, and is moving or stationary. To say this is not the same as affirming representationalism, of course. The claim at this point of the argument is not that colour experience is exhausted by how the experience represents things to be - the distinctive thesis of representationalism, but that colour experience is essentially representational, be it exhaustively so or not. Although I accept the stronger claim, it is the weaker one that is important for spelling out the opacity puzzle and is the contention that is all but axiomatic, or so I claim.

There is a tension between the causal claim and the representational claim. The causal claim says that in the normal case it is redness that causes things to look red. Now we know what causes things to look red - certain physical properties. To fix the discussion, I will adopt a currently popular candidate mentioned already - a certain reflectance profile, and suppose that the normal cause of something's looking red is a certain reflectance profile, RRP. ${ }^{4} \mathrm{We}$ can, therefore, conclude from the causal claim that redness $=\mathrm{RRP}$, and correspondingly that yellowness $=$ YRP, and so on.

The tension comes from the fact that the representational claim would seem to tell us that being red or redness is the property that something's looking red represents things to have. It would seem, therefore, to follow from the identification of redness with RRP that X's looking red represents that X has RRP. However, it does no such thing. If looking red did so represent, we would not have had to do all that work to find out about RRP. 
The situation can be displayed as follows:

(1) Redness or the property of being red is the normal cause of looking red. (Causal axiom)

(2) The property that looking red represents things as having is being red. (Representation axiom)

(3) The normal cause of looking red = RRP. (Empirical claim)

Ergo, the property looking red represents things as having is RRP. (Trouble)

The contrast with shape is marked. Being square is the property $X$ 's looking square represents $\mathrm{X}$ as having. The normal cause of X's looking square is being square. No problem. Similarly, moving is the property X's looking to be moving represents it as having, and it is also the property that typically causes $\mathrm{X}$ to look to be moving.

It will now be clear why we can be casual about the science. The trouble would be as bad no matter what the normal cause of looking red turns out to be, as long as it is some relatively obscure physical property, as we know it will be. For any obscure $\mathrm{P}$, the result that $\mathrm{X}$ 's looking red represents that $\mathrm{X}$ is $\mathrm{P}$ is trouble. This is why there is such a marked contrast with the case of shape perception: we all know which physical property typically makes things look square, and that it is the very property that looking square represents things as having.

\section{THREE MISTAKEN RESPONSES TO THE OPACITY PUZZLE}

First, it would be wrong to say that the puzzle is simply the old puzzle about the opacity of belief re-run for representation. Whatever should be said about the possibility, or apparent possibility, that in a case where $\mathrm{a}=\mathrm{b}, \mathrm{S}$ believes that $\mathrm{a}$ is $\mathrm{F}$ but does not believe that $\mathrm{b}$ is $\mathrm{F},{ }^{5}$ we know that one wrong thing to say is that it is a case where something, a, has the property of being believed to be $\mathrm{F}$ by $\mathrm{S}$, and the same thing, $\mathrm{b}$, has the property of not being believed to be $\mathrm{F}$ by $\mathrm{S}$. To say that would be to violate Leibnitz's Law. But our problem is precisely that we seem to have good reason to hold of a single property - redness that it is both how things are being represented to be when something looks red, and is the normal cause of looking red, and yet we know that all plausible candidates to be the normal cause are not plausible candidates to be how things are being represented to be. 
Secondly, some might bite the bullet and conclude that looking red does, after all, represent that something is RRP, this being a discovery of colour science. Now there is a sense of representation that would allow this. There is a sense in which my hair temperature at $t$ represents the temperature of the air near my head at $t$ by virtue of typically co-varying with it, but this is not the sense of representation that concerns us here. We are concerned with the sense in which perceptual experience represents that things are thus and so in a sense tied to one's experience being a kind of open invitation to believe, ${ }^{6}$ a defeasible invitation but an invitation that one accepts, absent defeaters. To this extent we are talking about conceptual content. When something looks a certain colour to one, very often the content will be non-conceptual in the sense that one has no word for the precise shade, but it will be conceptual in the sense that there is a way things are that one is being invited to accept as how things in fact are. X's looking red does not plausibly essentially involve anything that could be described as an open invitation, defeasible or not, to believe that $\mathrm{X}$ is RRP.

Thirdly, it might be suggested that we embrace eliminativism about colour, indeed that we should see the opacity puzzle - our argument to trouble from the causal and representation axioms - as a way to argue for eliminativism about colour. There is no property which is both the normal cause of something's looking red and how looking red represents that something to be; therefore, there is no such property as red. I think there are two problems with this response.

The first is that it seems too good an argument for eliminativism about colour. The argument makes no reference to the kind of phenomena that are usually taken to be the basis for eliminativism. There is nothing about metamers and no reference to whether or not there are suitable commonalities to be found in objects that look the same colour in normal circumstances. The argument would work even if there were simple explanations of things looking coloured in terms of physical properties that stood in the sameness, difference and similarity relations we intuitively apply to the colours. The kinds of considerations often marshalled in favour of the view that the world is not coloured - for instance, that there is no suitable property in common to things that look red in normal circumstances that marks them off from things that look green, that things that look orange are not in themselves more similar to things that look yellow and to things that look red than they are to things that look blue, and so on 
- would not be needed. This is the sense in which we would have too good an argument for eliminativism.

The second problem comes from what we learn from the famous reduction of the thermodynamic theory of gases. It is right to identify the properties of the thermodynamic theory with the appropriate properties of the kinetic-molecular theory. But we can raise the same kind of opacity problem for heat and temperature as we did for colour. The sensation of heat represents that what is being felt is hot. That which causes things to feel hot is a certain molecular energy property. But the sensation of heat does not represent (in the relevant, 'perception', invitation to believe, sense of representation) that what is felt has that molecular energy property. Similar remarks apply to temperature. However, it is wrong to infer from these facts which amount to observing that heat and temperature display an opacity that makes them like colour and unlike shape and motion that we should be eliminativists about heat and temperature, that we should deny that heat and temperature are features of our world.

\section{THE DUAL PROPERTIES RESPONSE TO THE OPACITY PUZZLE}

\subsection{The Example of Heat Suggests a Way of Looking at the Opacity Puzzle for Colour.}

Heat is one of a number of cases where we need to keep track of two properties where we might have thought that there is only one property we need to recognise. There is the role that heat plays, and the property of having a property that plays that role. The distinction is like that between the property that kills the most - that is, the property that in fact does the killing, and the property of having whatever property it is that does the killing. In the familiar jargon, the first is the realiser property, the second is the role property. ${ }^{7}$ Or consider the relationship between the grammatical sentences of Japanese and those of English. They have something in common - both are 'OK' constructions in their respective languages, but the constructions that are grammatical in Japanese are very different from those that are grammatical in English. The role played is the same, but that which plays or realises the role played is very different. And when we say that a sentence is grammatical, we can equally be thought of as ascribing the role property or the realiser property.

I think we should and must say something similar in the case of colour. Here is a way to look at the difference between, for example, 
colour and shape, between cases where the properties we track vary sharply in their transparency. As we evolved, it was important that our senses kept track of various features of our world. Some of these features our senses keep track of qua the properties they are, some we keep track of qua the roles they play. Examples of the first are shape, position and motion. Heat is an example of the second. In the first kind of case, an $\mathrm{F}$ experience represents that something is $\mathrm{F}$; in the second kind of case, an $\mathrm{F}$ experience represents that something has the property playing the $\mathrm{F}$ role. In the first case, the perceptual experience represents the property per se; in the second case, the experience represents the property qua the role it plays (this may or may not be a purely causal matter). ${ }^{8}$

We are now ready to look afresh at the opacity puzzle for colour. Suppose that X looks red to me. There is the property - the redness that I am putatively responding to; the property that is upstream from my experience. But there is also the fact that I see $X$ as very similar in a striking respect to all the other red things. Moreover, I see it as very different from green things and as more like pink things than blue things. What is more, these similarity and difference relations have, as we might put it, a much higher profile than the similarity and difference relations in cases like the duck-rabbit. Seeing the duck-rabbit as a rabbit is a different experience from seeing it as a duck, and the difference is a matter in part of which similarity class one sees it as belonging to - the rabbits or the ducks. But we can isolate an element in our experience that is neutral between the two. There is a certain shape qua shape, and we know what it would be like to see that very shape, the one we see either as a duck shape or a rabbit shape, without seeing it as either a duck shape or a rabbit shape. In the same way, we have some kind of understanding of what it is like to be motion-blind in the sense of being able to see an object as being at different places at different times without seeing it as moving from one place to another. ${ }^{9}$ However, in the case of colours, we cannot imagine what it would be like to see them without seeing them as standing in the famous similarity and difference relations. Take the relations away and you take away colours as seen features. We cannot make sense, for instance, of seeing something as red at the same time as failing to see it as more like pink than green, or of seeing something as black without seeing it as more like dark blue than pale yellow, or of seeing something as orange without seeing it as some kind of mixture of red and yellow. ${ }^{10}$

In sum, I am suggesting that when we philosophise about colour, we need to distinguish two properties. The first is the property that 
acts on us when something looks, say, red, in normal circumstances, and which is shared between red things and absent from green things, and likewise for all the colours. This is the property that is plausibly identified with reflectances or some suitable generalisation of reflectances, if that is how the science turns out. The other is a property of the first property. There are many possible views about the exact nature of this second property but it will be a property like being similar to so and so, and different from such and such, and being affected by light in so and so a way etc. and, more generally, the properties the folk qua ascribe to the colours; the properties we can know about without the benefit of colour science; the properties codified in the colour solid. It will be useful to have a tag for this role and I'll use ' $\operatorname{Ro}(-)$ ' for the role played by ' - '. We can think of the first as the realiser property and the second as the role property.

This does not mean that when we see $\mathrm{X}$ as red (yellow, etc.), there is some mysterious duality in how things are being represented to be. We represent that $\mathrm{X}$ has the property, whatever it is, that has the such and such properties - the properties that make up the red (yellow, etc.) role. There is one way things are being represented to be, namely, that of having the property that has such and such properties. And because such and such properties are precisely those essential to being red (yellow etc.) - being more similar to pink than green (being more similar to orange than red, etc.) and all that - the property that has them is a very good candidate to be red (yellow, etc.).

Here, then, is how we escape the opacity puzzle. When faced with

(1) Redness or the property of being red is the normal cause of looking red. (Causal axiom)

(2) The property that looking red represents things as having is being red. (Representation axiom)

(3) The normal cause of looking red = RRP. (Empirical claim)

Ergo, the property looking red represents things as having is RRP. (Trouble)

we argue that there is a fallacy of equivocation. We distinguish redness in the sense of the realiser property from redness in the sense of the role property, and note that premise 1 is only true as a claim about the realiser property, whereas premise 2 is only true as a claim about the role property. This blocks the derivation of the conclusion. If we call the first property redness or red, and the second being red, red is the possibly disjunctive property that satisfies the causal axiom, 
and being red is the property that satisfies the representation axiom: red $=$ the property that plays $\mathrm{Ro}(\mathrm{red})$; being red $=$ the property of having the property that plays Ro(red). ${ }^{11}$

\section{REPRESENTATIONALISM (PROPER)}

I said that the experience of seeing something as red represents that that something has the property that has such and such properties, and I have been arguing that we need to invoke the realiser-role distinction to explain how this might be true consistently with what we know about what makes things look one or another colour if we wish to avoid eliminativism about colour. But so far I have made no trouble for the via media. It is representationalism proper that makes the trouble for the via media. As I said at the beginning, representationalism is a topic for a paper in its own right but I should, I think, indicate why I find it so attractive and, of course, say how I understand it.

We have been taking as a given that experience is essentially representational. Representationalism holds in addition that experience is exhaustively representational, that how an experience represents things as being exhausts its experiential nature. Representationalism is not, however, the view that the content of an intentional state determines its nature qua mental state without remainder. That doctrine is uncontroversially false. A belief and a desire may have the very same content - I may both believe and desire that it will rain soon. Representationalism, as we will understand it, is the doctrine that it is the content of an experience plus the fact that the experience represents that that content obtains in the way distinctive of perception, which determines the experience's nature without remainder.

Part of the reason I find representationalism appealing is that the live issue, as I see things, is not between representationalism and the view that experience is not essentially representational. It is between representationalism, the exhaustion doctrine, and the view that experience has an essential representational element and, in addition, an extra that contributes to phenomenal feel, on the other. But in the latter case we should be able to vary the extra without affecting what is represented, and this we cannot do, or so it seems to me. Whenever someone describes a case where the 'feel' is varied, it seems to me that they thereby describe a case where how things are being represented to be has changed. ${ }^{12}$ Equally, if there is an 'extra', we should be able to have it by itself minus the representation, and that seems to be impossible. 
Another part of the reason I find representationalism appealing is that I find accounts of alternatives to representationalism implausible. ${ }^{13}$ For instance, some hold that your perceptual state represents that $\mathrm{X}$ is red by having some property distinct from red, red* as it might be, a property of the experience qua experience, as opposed to qua object which is a part of the world putatively confronting you. ${ }^{14}$ This seems to me an implausible multiplication of properties. For, first, I accept the lesson of diaphanousness, the view that the properties of experience qua experience are the putative properties of what is experienced, and the putative properties of what is experienced are nothing more or less than the properties our experience represents things to have, $\mathrm{X}$ in our example. ${ }^{15}$ When $\mathrm{X}$ looks red to me, I cannot find any part of the phenomenology to transfer, so to speak, to X; the phenomenology is one and all part and parcel of how $\mathrm{X}$ itself is being represented to be. Secondly, the view means that experience is no longer essentially representational; its nature qua experience is secured by its being red*, and that in itself does not require that the experience per se 'says' anything about how $\mathrm{X}$ is. Finally, it is hard to see how transferring red* amounts per se to representing that $\mathrm{X}$ has some different property, red. Or take the experience of X's looking square. The puzzle is how the experience's being square*, a property distinct from being square, when transferred to $X$, in and of itself says that $\mathrm{X}$ is square?

\section{REPRESENTATIONALISM VERSUS THE VIA MEDIA}

According to representationalism, the nature of perceptual experiences in general and of colour experiences in particular are given exhaustively by the way they represent the world that confronts us as being. As we said above, representationalism accepts diaphanousness, the view that the properties of experience are putative features of that which is experienced. It follows that representationalism implies that the conditions on what it takes to be red, while being imposed by the nature of colour experience, are conditions on how our world is. Subjectivists love to describe scenarios where they make major changes to the colours things look to have they talk of the effects of sodium lamps, what happens at dusk, inverting colour lenses, of 'Martians' who have one more cone that we do, and so on - and proceed to invite us to concede that the only non-arbitrary responses to questions about what the real colours are are to let apparent colours determine our assignments of 
colours except in highly deviant cases (the kind of cases where X's making someone sick would not show that $\mathrm{X}$ is a poison). Of course, say subjectivists, we can rule that the real colour is the colour something looks to the typical human in daylight, but the arbitrariness of this ruling only brings out the truth of the subjectivist cum dispositional message. However, representationalism about perceptual experience tells us that each apparent colour is a representational state: each state of something's looking to have such and such a colour represents that things before one are thus and so. It is then a matter for the world whether the things before one are thus and so; one's state sets the question but the world answers it.

Here is a way to put the key point. We can all agree that there is an intimate link between colour and colour experience. It is no accident that the way we acquire the concept of colour is through having things looking coloured to us, despite the fact that other ways are possible in principle. We got the concept of a quark via its role in fundamental physical theory but nothing like that happened with red. We simply latched onto that visually conspicuous property that confronts us when we see ripe tomatoes, blood and the like. The via media makes the link between colour and colour experience with nondeviant causal connections, which means that, at the end of the day, what gets caused in one is very important for settling the colours things have, and so we get a subjectivist cum dispositional account of colour from the via media. However, the representationalist makes the link with the content of colour experiences, and, because colour experiences represent things around us as being thus and so, at the end of the day, what settles whether or not something is red is whether or not it satisfies the condition on how things are around one given by the 'thus and so'.

Properties like being uncomfortable as a property of chairs, or being poisonous as a property of substances are dispositional cum subjective because a chair's being uncomfortable is answerable at bottom to whether or not the chair typically causes discomfort, and a substance's being poisonous is answerable to whether or not it typically causes those who ingest it to become ill. By contrast, an object's being red is answerable to whether or not it is as the experience of looking red represents it to be. In the first kind of case, what matters for having the assigned property is not the nature of that which is assigned the property; it is the nature of that which gets caused by that which is assigned the property, plus the nature of the causal connection between the two - it needs to be 
non-deviant. In the second kind of case, the nature of that which is assigned the property is crucial; it needs to be as the experience represents it to be. The reason for the big difference goes back to the fact that uncomfortable chairs and poisons cause experiences in our bodies, experiences that represent that our bodies are thus and so. But when something looks red to us, the experience does not represent how our bodies are or how we are. The content concerns how the thing seen is.

Take, for illustration, the case of Martians who have, on all the standard tests, much better colour vision than any humans. What do we representationalists say to subjectivists' suggestions that this would merely show that they are better at 'colour for Martians' than humans are; that to say otherwise is like the mistake of saying that Martians who make many more discriminations on the score of comfort among armchairs should be employed to settle which chairs are really comfortable for humans. What we representationalists say is that there are two cases. One case is where the Martians and we have the same range of colour experiences. In this case, from representationalism, it will be true that how we and they represent things to be when we have colour experiences coincides. The difference will be that they are better than we are at determining when things are as they are being represented to be. The other case, the one more likely to be the actual one, is where how Martians are representing things to be differs from how we are representing things to be. In that case, we and Martians have different colour concepts and mean different things by colour words. If they make every discrimination we do and more besides, the plausible view will be that their concepts and meanings are more fine grained versions of ours - theirs' mark every boundary that ours do and more besides.

This is a kind of subjectivism but only about concepts and word meanings, not about the properties we and they are representing things to have. It is the recognition that the concepts and meanings are our and their concepts and meanings, respectively. Of course the point carries across to humans with defective colour vision. If Fred, a man with serious red-green colour blindness, says that $\mathrm{X}$ is red on the basis of how it looks to him, there are two possibilities. (i) Fred is seeking to ascribe the property we use 'red' for - in which case there is a good chance he is wrong. (ii) Fred is seeking to ascribe the property his experience represents $\mathrm{X}$ as having - a property which is wider in extension than the property we ascribe with the word 'red', though he may well not realise this - in which case there is a good chance he is right. ${ }^{16}$ The first case is one where Fred is likely to be 
wrong owing to bad colour vision. The second case is one where Fred is likely to be right but right about a different property from the property we are right about (when we are right). Neither case is support for subjectivist views of colour. What is true, of course, is that humans are much more likely to be making somewhat different claims about how things are when they use colour terms than is the case when they are using terms for shape and motion. Humans can have different concepts of red much more easily than different concepts of square. If you and I differ in the shape we use 'square' for, the difference will likely show up because shape matters conspicuously for how things move through space, and because there are agreed ways of measuring shape. But it is notorious that you and I can differ markedly in ability to discriminate colours without realising that we do and, according to representationalism, this will typically correspond with our having somewhat different colour concepts.

We can sum this up as follows. The via media says that (i) for X to be red is for $\mathrm{X}$ to have the objective property that normally causes things to look red, and (ii) that redness is that objective property. The representationalist alternative says that (i) for $\mathrm{X}$ to be red is for $\mathrm{X}$ to have the objective property that satisfies Ro(red), and (ii) that redness is that objective property. What's the big difference? The condition set by Ro(red) concerns how the world needs to be for something to be red, not how subject's have to be. It concerns how the world is being represented to be when something looks red, not how subjects are or would be. On the via media, the role is to be a typical cause of looking red; on the representationalist alternative, the role is to be as looking red represents things to be.

Having emphasised the non-subjective nature of the representationalist alternative, we should note that there is a kind semantic subjectivism in the representationalist alternative. Reflectances are not obvious features of our world. Still less obvious are the various relations they stand in. The same goes for any of the at all plausible candidates that physical realists might suggest for identification with the colours. This means that, though we could in principle have noted the relevant properties and roles they play - the roles we've used 'Ro ( - )' for - without the benefit of colour vision, in practice we have to latch onto the properties and patterns in the first place via things looking coloured to us. In practice, we had no alternative but to acquire the words and the concepts via having the various colour experiences. The word 'red' gets into English because English speakers have looking-red experiences and this is a highly 
non-accidental fact. This, though, does not mean that being red and being disposed to look red go hand in hand. We might have acquired the word and the concept through the machinations of brain scientists in a world where there were objects that were as looking red represents them to be but which, for one reason or another, did not normally cause things to look red. On the representationalist alternative, these objects would be red despite not being disposed to look red.

\section{SUBJECTIVISM BY THE BACK DOOR?}

I made the distinction between the via media and the representationalist alternative by emphasising that the condition set by Ro(red) concerns how the world needs to be for something to be red, not how subject's have to be. The key point is that colour experiences represent how the world is, not how we are or would be. But it might be objected that this is nothing more than dogma. Why shouldn't X's looking red represent that X is a typical cause of X's looking red, or something along these lines. The representationalist alternative would then not be an alternative at all; we would be back in the subjectivist cum dispositionalist camp. ${ }^{17}$ The representational content in and of itself would imply that normally causing red sensations was enough to meet the requirement for being red.

However, representationalism cannot allow that the content of looking red is in part a matter of looking red itself. One reason is that experience represents how the world is, not putative facts about experience itself. That is the lesson of diaphanousness. Another reason is that such a suggestion would be circular, and viscously so in the sense of leading to an infinite regress. For representationalists, there must be a thus and so that $\mathrm{X}$ is being represented to be when $\mathrm{X}$ looks red. But if the thus and so is in part that subjects represent that things are thus and so, we are off on an infinite regress. The content cheque can never be cashed.

\section{ACKNOWLEDGEMENTS}

I am much indebted to the discussion at Bielefeld where an early version of this paper was presented. 


\section{NOTES}

${ }^{1}$ Dispositionalist accounts in the traditional sense of ones in terms of dispositions to look coloured, as opposed to ones in terms of dispositions to modify light in certain ways, for example.

2 See, e.g., Jackson and Pargetter (1987) and Jackson (1996).

${ }^{3}$ For a recent defence with many references to the literature, see Tye (2000). For some reservations about the particular version Tye espouses, see Jackson (2004). With hindsight I regret not believing more of what David Armstrong said many years ago, starting with Perception and the Physical World (1961) and Bodily Sensations (1962), although those books pre-date the use of the notion of representation as a way of expressing matters. It was reading Lycan (1996) that finally converted me to representationalism, although not to quite the kind he avows.

${ }^{4}$ There is an interesting generalisation of reflectance profiles designed to cover, for instance, objects that are, to one extent or another, transparent, described in Byrne and Hilbert (2003).

5 I say 'possibility or apparent possibility' as some hold views about proper names that mean that belief that $a$ is $F$ goes along with belief that $b$ is $F$, whenever $a=b$. A recent example is Thau (2002, ch. 4).

${ }^{6}$ I borrow the phrase from Foster (2000, p. 105).

7 See, e. g., Jackson and Pettit (1988), but the terminology of course goes back well before 1988. I am indebted to Andreas Kemmerling for spotting a blunder in an earlier formulation of the point in the text.

${ }^{8}$ In the final section I argue that this role cannot, given representationalism, be that of causing, or typically causing, an $F$ experience.

${ }^{9}$ I am here indebted to lunches with Philip Pettit.

10 Armstrong (1968, p. 275) says that 'our concept of red is all blank or gap'. I think (hope) this is the same point in other words.

11 Some of my fellow physical realists about colour insist that there is no need to postulate two properties. But when we believe that ripe tomatoes are red, what colour do we believe ripe tomatoes to have? Not some colour other than red surely. But we do not believe them to have such and such a surface reflectance property or anything like that (or need not). So we physical realists had better allow some property other than having such and such a reflectance to be identical with something that gets a colour name.

12 For a discussion of some alleged counter-examples, see Tye (2000, ch. 4).

13 Thanks here to a discussion with John O'Dea.

14 It is sometimes suggested by qualia realists of a projectivist bent that the property of the experience and the property that $X$ is represented to have is one and the same. But this cannot be right for shape and distance away. $X$ will typically be represented to be a certain shape and distance away, but no-one bar hardline sense datum theorists (like my former self) think that shape and distance away are properties of the experience. But the colour is represented to be a property of the very same thing that is a certain shape and distance away.

15 In the terms of Moore (1903/1922). Of course, the use of diaphanousness (following, e.g., Harman, 1990), to argue for the representational cum intentional position) is not one Moore would have accepted. I take the point that immediately follows in the text to be the one Harman $(1996, \S 4.1)$ is making. However, Harman uses representationalism to defend a version of the via media, if I understand his final position aright. 
16 Strictly, there's a third possibility - that it is indeterminate which of (i) and (ii) obtains.

17 As David Chalmers pointed out to me.

\section{REFERENCES}

Armstrong, D.: 1961, Perception and the Physical World, Routledge and Kegan Paul, London.

Armstrong, D. M.: 1962, Bodily Sensations, Routledge and Kegan Paul, London.

Armstrong, D. M.: 1968, A Materialist Theory of the Mind, Routledge, London.

Byrne, A. and D. R. Hilbert: 2003, 'Color Realism and Color Science', Behavioral and Brain Sciences 26, 3-21.

Foster, J.: 2000, The Nature of Perception, Oxford University Press, Oxford.

Harman, G.: 1990, 'The Intrinsic Quality of Experience', Action Theory and Philosophy of Mind, Philosophical Perspectives 4, 31-52.

Harman, G.: 1996, 'Explaining Objective Color in Terms of Subjective Experience', in E. Villanueva (ed.), Perception, Philosophical Issues, Vol. 7, Ridgeview, Atascadero/CA, pp. 1-18; reprinted in A. Byrne and D. Hilbert (eds.), Readings on Color, Vol. I, MIT Press, Cambridge/MA, pp. 247-261.

Jackson, F.: 1996, 'The Primary Quality View of Color', in James Tomberlin (ed.), Metaphysics, Philosophical Perspectives, Vol. 10, Blackwell, Cambridge/MA, pp. 199-219.

Jackson, F.: 2004, 'Representation and Experience', in H. Clapin, P. Slezack, and P. Staines (eds.), Representation in Mind: New Approaches to Mental Representation, Elsevier, Amsterdam, pp. 107-124.

Jackson, F. and R. Pargetter: 1987, 'An Objectivist's Guide to Subjectivism about Colour', Revue International de Philosophie 41, 127-141. Reprinted in A. Byrne and D. Hilbert (eds.), 1997, Readings on Color, Vol. I, MIT Press, Cambridge/MA, pp. 67-79.

Jackson, F. and P. Pettit: 1988, 'Functionalism and Broad Content', Mind 97, 381-400.

Lycan, W. G.: 1996, Consciousness and Experience, MIT Press, Cambridge/MA.

Moore, G. E.: 1903, 'The Refutation of Idealism', Mind 12, 433-453, reprinted in G. E. Moore, 1922, Philosophical Studies, Routledge and Kegan Paul, London, pp. $1-30$.

Thau, M.: 2002, Consciousness and Cognition, Oxford University Press, Oxford.

Tye, M.: 2000, Consciousness, Color, and Content, MIT Press, Cambridge/MA.

Research School of Social Science

Australian National University

Canberra

Australian Capital Territory

Australia 0200

E-mail: Frank.Jackson@anu.edu.au 